Indexed by

\title{
PREVENTING ROLLOVER PHENOMENON WITH AN ACTIVE ANTI-ROLL BAR SYSTEM USING ELECTRO-HYDRAULIC ACTUATORS: A FULL CAR MODEL
}

\section{Vu Van Tan}

University of Transport and

Communications, Faculty of

Mechanical Engineering,

Department of Automotive

Mechanical Engineering,

Hanoi, Vietnam

Key words: active anti-roll bar system, electro-hydraulic actuator, roll stability, optimal control, linear quadratic regulator controller

\section{Cite article:}

Vu, V. T. [2021]. Preventing rollover phenomenon with an active anti-roll bar system using electro-hydraulic actuators: a full car model. Journal of Applied Engineering Science, 19(1), 217 - 229. DOI:10.5937/jaes0-28119 


\title{
PREVENTING ROLLOVER PHENOMENON WITH AN ACTIVE ANTI-ROLL BAR SYSTEM USING ELECTRO-HYDRAULIC ACTUATORS: A FULL CAR MODEL
}

\author{
Vu Van Tan* \\ University of Transport and Communications, Faculty of Mechanical Engineering, \\ Department of Automotive Mechanical Engineering, Hanoi, Vietnam
}

This paper discusses the role of the active anti-roll bar system in order to enhance the roll stability of cars, thereby preventing rollover phenomenon in high speed emergency situations. First, an integrated full car model is proposed including the longitudinal, lateral, vertical motions and an electro-hydraulic actuator model. In this full car model, the control signal being the input current which is supplied to the actuators to create the active torques to improve the car's stability. This is the most general model in theory to study this active roll control system and is a big step forward compared to previous related studies. The optimal LQR control method has then been used to synthesize the controller based on the integrated model with 26 degrees of freedom. The criteria used to assess the vehicle roll stability are the sprung mass roll angle and the interactive force between the wheels and the road surface. The simulation results in the frequency domain and the validation in the time domain through the CarSim software's nonlinear car model clearly show the advantages of this active system with an optimal LQR controller in preventing vehicle rollover.

Key words: active anti-roll bar system, electro-hydraulic actuator, roll stability, optimal control, linear quadratic regulator controller

\section{INTRODUCTION}

Nowadays, the automobile has become the main means of transportation in all countries of the world. The positive contributions of these vehicles have improved the economic development and the quality of life. However, vehicle accidents also happen quite often and cause thousands of casualties every day on a global scale. Among them, the accidents caused by vehicle rollover are often the ones with most serious consequence. Two basic types of vehicles: cars and heavy vehicles have been studied in details to reduce the risk of the rollover phenomenon [1].

For heavy vehicles, due to the large total weight and high center of gravity, the rollover phenomenon occurs at a higher frequencies, even when they are affected by side wind, etc [2]. Nowadays, modern commercial heavy vehicles can use a brake system to prevent the rollover phenomenon. However, new studies have suggested the use of an active anti-roll bar system to perform this task. The results of theoretical and experimental studies have been conducted with advanced control methods $[3,4]$.

For cars, the rollover phenomenon usually occurs when they are moving at high speeds and during emergencies. In order to prevent this phenomenon, several active systems have been studied and applied in real cars, such as: brake, suspension, steering and anti-roll bar [5-7]. However, the Active Anti-Roll Bar (AARB) system is currently considered as the most promising and it can directly supply the restoring moment. In addition, due to the low weight of the car, the active torque generated from the actuators is not too large, resulting in a relatively compact system structure $[8,9]$. Therefore, the study of installing this system on real cars is getting more and more attention.

The previous studies often used a half vertical car model to build dynamical equations and design the controllers. They considered the excitation from the road surface that causes the rollover situation. However, this model has the disadvantage, which is not being able to evaluate the entire roll motion properties and does not consider the role of the lateral inertial force affecting this phenomenon. In the studies of $[10,11]$, a more advanced model has been proposed including a half vertical car model and a bicycle longitudinal motion. The authors then used PID, LQG control methods to design the controllers for the AARB system.

In studies of the Hungarian Academy of Sciences [1214], an Electro-Hydraulic (EH) actuator combined with a half vertical car model, have been proposed. The simulation results with the LQ and LPV controllers have shown the superiority of the proposed scheme. They are, however, more focused on establishing controller construction methods than on the goal of assessing the overall state of cars. That is shown in particular is that they have not yet evaluated the rollover characteristics of cars as well as the results in the frequency domain.

This paper proposes a complete car model to assess the effectiveness of the AARB system, thus the main contributions are listed as follows:

- An integrated model is proposed by combining a full car model comprising the lateral, longitudinal and vertical motions, with an $\mathrm{EH}$ actuator model on the two axles. Then the source of excitation includes the 
road surface at the four wheels and the steering angle from the driver. The control input is the current supplied to the two actuators. This model has the outstanding advantage of being the closest to the system structure on an actual car. Therefore, it allows a relatively accurate assessment of the vehicle rollover characteristics.

- $\quad$ The optimal control method LQR (Linear Quadratic Regulator) is used to synthesize the controller for the AARB system. By cleverly selecting a performance index that includes all the variables of the state vector, the synthesis of the weighting matrices is simplest. During the controller design, the role of the sprung mass roll angle, the vertical displacement of the wheels, as well as the interaction force between the wheels and the road surface is emphasized to ensure the goal of preventing rollover phenomenon.

- The simulation results conducted in the frequency domain indicates the response of the signals, which are related to the car's roll stability from the disturbance of the steering angle. The transfer function magnitude from the steering angle is reduced within the frequency range of interest, so the control target has been satisfied.

- The validation of the above proposed method with a highly nonlinear car model from the $\mathrm{CarSim}^{\circledR}$ software is performed. The simulation results in a typical double lane change scenario (ISO 3888) with the high speeds from $60 \mathrm{~km} / \mathrm{h}$ to $160 \mathrm{~km} / \mathrm{h}$ shows that the roll stability of the car has increased about $30 \%$ when compared to the car using a conventional passive suspension system.

The paper structure is organized in six main sections: Section 2 introduces the integrated full car model. Section 3 describes the optimal LQR controller design for an AARB system. The simulation results conducted in the frequency domain are summarized in Section 4. In section 5 the validation by a nonlinear car model from CarSim software is presented. Some conclusions and potential extensions are given in Section 6.

\section{AN INTEGRATED FULL CAR MODEL}

\section{An electro-hydraulic actuator model}

The model of the EH actuator is described in Figure 1. It has two main parts of an electronic servo-valve and a hydromotor. The active torque generated by this actuator is $M_{\text {act }}$ at the hydromotor, which has two chambers, and it is separated by different vanes. The pressure difference between the vanes creates the active torque of the system on the central shaft. It should be noted that this central shaft has an angle of rotation limited to the range of no more than 120 degrees. The anti-roll bar in this layout is divided into two separate halves and are connected together by the hydromotor $[12,15]$. The hydromotor's shaft is attached to the one side of the anti-roll bar, while its housing is connected to the rest. In the case the

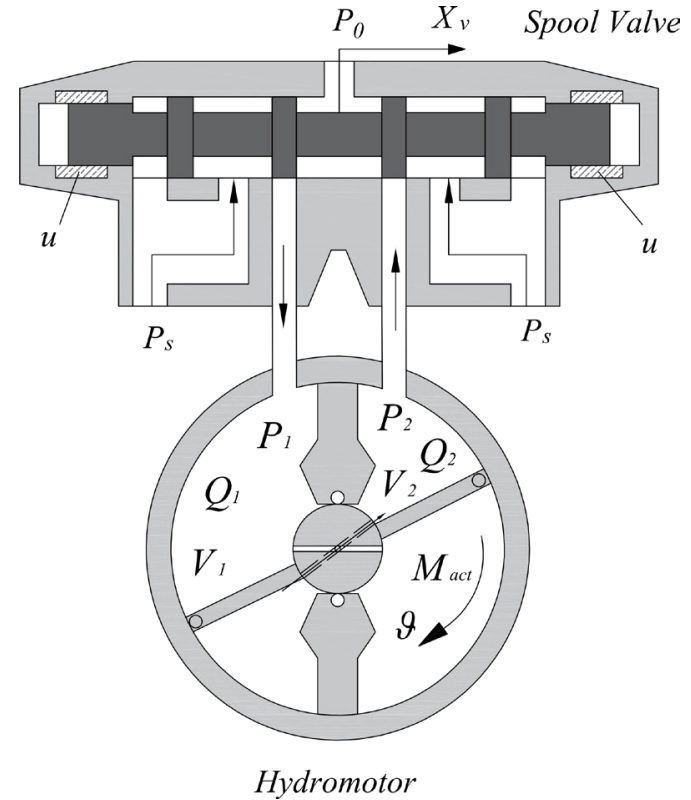

Figure 1: Model diagram of an EH actuator [12]

sprung mass is tilted, an active torque appearing in the housing of the hydromotor counteracts this inclination, thanks to the pressure difference in the two chambers of the hydromotor which is supplied by a hydraulic pump.

The electronic servo-valve used in this study is a symmetric $4 / 2$ four ways valve. We assume that the effects of the flow forces and hysteresis are ignored, thus the dynamical equation of this valve is modeled as a second order linear system in Equation (1). This equation is a linear dependence between the spool displacement $X_{v}$ and the input current $u$.

$\frac{1}{w_{v}^{2}} \ddot{X}_{v}+\frac{2 D_{v}}{w_{v}} \dot{X}_{v}+X_{v}=K_{v} u$

where $K_{v}=\frac{Q_{N}}{\sqrt{\Delta P_{N} / 2}} \frac{1}{u_{v \max }}$ is the gain of the servo-valve model. With $Q_{N}$ is the rated flow at the rated pressure, $P_{N}$ - pressure drop and $u_{v \max }$ - maximum rated input current at the rated flow.

Because the orifices are arranged symmetrically, the load flow $Q_{L}$ of the oil flowing through the servo-valve is linearized as follows $[2,16]$ :

$Q_{L}=K_{q} X_{v}-K_{c} P_{L}$

Here $K_{q}$ is the valve flow gain, $K_{c}$ is pressure coefficient. The difference pressure between two chambers of the hydromotor showing the relationship between the load flow and its rotation angle is expressed as follows:

$\dot{P}_{L}=\frac{4 \beta_{E}}{V_{t}}\left(Q_{L}-V_{p} \vartheta+c_{l 1} \dot{\vartheta}-c_{l 2} P_{L}\right)$

Following (2) and (3), the differential equations describing the difference pressure is determined as:

$$
\begin{aligned}
\dot{P}_{L} & =\frac{4 \beta_{E}}{V_{t}}\left(K_{q} X_{v}-K_{c} P_{L}-V_{p} \vartheta+c_{l 1} \dot{\vartheta}-c_{l 2} P_{L}\right) \\
& =\frac{4 \beta_{E}}{V_{t}} K_{q} X_{v}-\frac{4 \beta_{E}}{V_{t}} P_{L}\left(K_{c}+c_{l 2}\right)-\frac{4 \beta_{E}}{V_{t}} V_{p} \vartheta+\frac{4 \beta_{E}}{V_{t}} c_{l 1} \dot{\vartheta}
\end{aligned}
$$


The rotation angle of hydromotor generated by the difference pressure between the two chambers is determined by the following equation:

$J \ddot{\vartheta}=-d_{a} \dot{\vartheta}+V_{p} P_{L}$

The active torque is generated by the actuator as follows:

$M_{a c t}=2 P_{L} A_{v} a_{a r n}$

Combining the equations from (1) to (6), the general differential equation of the $\mathrm{EH}$ actuator model is determined in the following equation:

$$
\left\{\begin{array}{l}
\ddot{X}_{v}=K_{v} u w_{v}^{2}-2 D_{v} \dot{X}_{v} w_{v}-X_{v} w_{v}^{2} \\
\dot{P}_{L}=\frac{4 \beta_{E}}{V_{t}} K_{q} X_{v}-\frac{4 \beta_{E}}{V_{t}} P_{L}\left(K_{c}+c_{l 2}\right)-\frac{4 \beta_{E}}{V_{t}} V_{p} \vartheta+\frac{4 \beta_{E}}{V_{t}} c_{l 1} \dot{\vartheta} \\
\ddot{\vartheta}=-d_{a} \frac{\dot{\vartheta}}{J}+V_{p} \frac{P_{L}}{J} \\
M_{a c t}=2 P_{L} A_{v} a_{\text {arn }}
\end{array}\right.
$$

In Equation (7), the actuator output is the active torque $M_{\text {act }}$ and the current $u$ is its input. The symbols and parameters of the $\mathrm{EH}$ actuator model are summarized in

\begin{tabular}{|c|c|c|c|}
\hline Symbols & Description & Value & Unit \\
\hline$K_{v}$ & $\begin{array}{c}\text { Gain of the servo-valve } \\
\text { model }\end{array}$ & 0,523 & $\mathrm{~m} / \mathrm{A}$ \\
\hline$D_{v}$ & $\begin{array}{l}\text { Valve damping } \\
\text { coefficient }\end{array}$ & 0,0071 & - \\
\hline$K_{q}$ & Valve flow gain & 11,02 & $\mathrm{~m}^{2}$ \\
\hline$K_{c}$ & Pressure coefficient & $4,2.10^{-11}$ & $\mathrm{~N} / \mathrm{m}^{2}$ \\
\hline$\beta_{E}$ & Effective bulk modulus & 6890000 & $\mathrm{~Pa}$ \\
\hline$V_{t}$ & $\begin{array}{l}\text { Total volume under } \\
\text { pressure }\end{array}$ & 0,0014 & $\mathrm{~m}^{3}$ \\
\hline$V_{p}$ & $\begin{array}{l}\text { Proportional to the } \\
\text { areas of vane } \\
\text { cross-sections }\end{array}$ & $1,95.10^{-4}$ & $\mathrm{~m}^{3}$ \\
\hline$c_{11}$ & $\begin{array}{l}\text { Parameters of the } \\
\text { leakage flow }\end{array}$ & $7,85.10^{-15}$ & $\mathrm{~m}^{3} / \mathrm{Pa}$ \\
\hline$c_{12}$ & $\begin{array}{c}\text { Parameters of the } \\
\text { leakage flow }\end{array}$ & $3,14.10^{-6}$ & $\mathrm{~m}^{3} / \mathrm{Pa}$ \\
\hline$J$ & $\begin{array}{c}\text { Moment of inertia of } \\
\text { the hydromotor: vanes, } \\
\text { shaft }\end{array}$ & 5 & $\mathrm{~kg} / \mathrm{m}^{2}$ \\
\hline$d_{a}$ & Damping constant & 1000 & $\mathrm{Ns} / \mathrm{m}$ \\
\hline$A_{v}$ & Area of the vanes & 0,0026 & $\mathrm{~m}^{2}$ \\
\hline$A_{\text {arm }}$ & $\begin{array}{l}\text { Arm length of the ARB } \\
\text { in the longitudinal } \\
\text { direction }\end{array}$ & 0.2 & $\mathrm{~m}$ \\
\hline
\end{tabular}
Table 1.

Table 1: The symbols and parameters of the EH actuator model [12-14]

\section{Full model of a car}

Most of the previous studies on the AARB system used a half vertical model with the only source of excitation from the road surface. This model has the advantage that it is simple to synthesize the controller but it is not detailed enough to fully describe the rollover characteristics of cars. Figure 2 shows a full car model with 9 Degree Of Freedom (DOF), where Figure 9a is the lateral and longitudinal motions and Figure $2 \mathrm{~b}$ is a vertical motion.

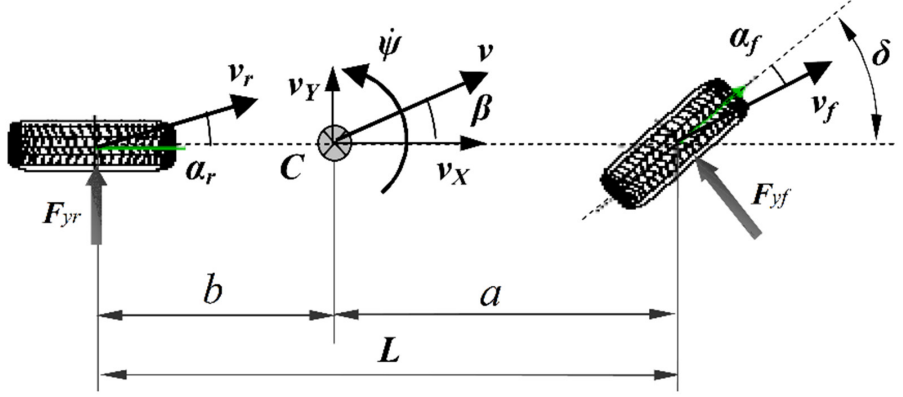

(a)

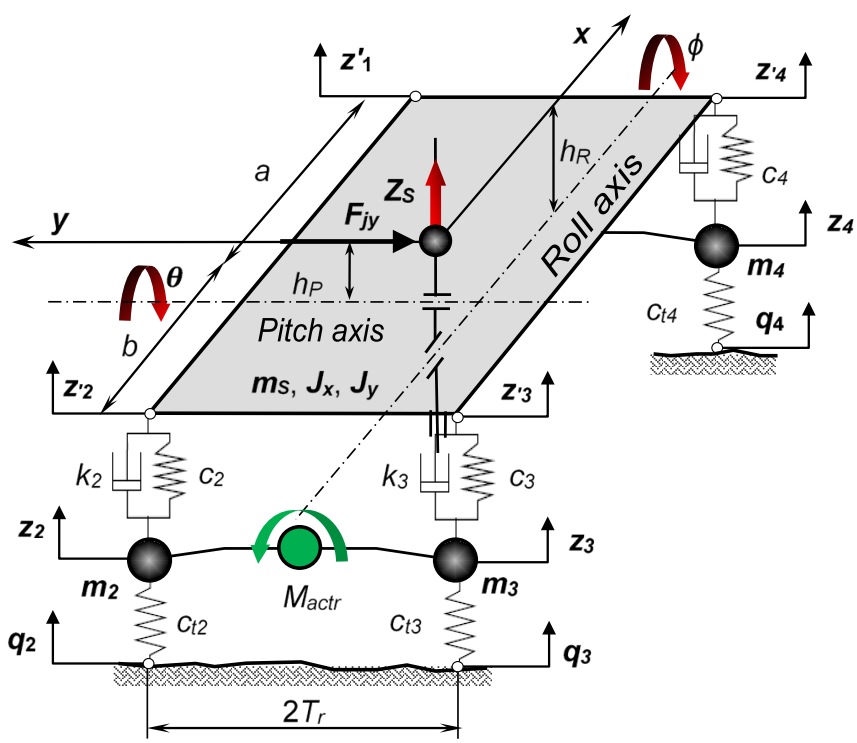

(b)

Figure 2: Full car model, lateral \& longitudinal (a) and vertical (b) motions

When the driver changes the steering angle as shown in Figure 2a, at the car's Center of Gravity (CoG), a lateral inertial force $F_{j y}$ appears. The dynamical equation of this motion is determined as follows [17]:

$$
\left\{\begin{array}{l}
m v \dot{\beta}+\left(m v+\frac{a C_{f}-b C_{r}}{v}\right) \dot{\psi}=C_{f} \delta-\left(C_{f}+C_{r}\right) \beta \\
I_{z z} \ddot{\psi}=a C_{f} \delta-\left(a C_{f}-b C_{r}\right) \beta-\frac{\left(a^{2} C_{f}+b^{2} C_{r}\right)}{v} \dot{\psi}
\end{array}\right.
$$

For the vertical motion in Figure $2 b$, there are two excitation sources: the lateral inertial force $F_{j y}$ and the excitation from the road surface at the four wheels $q_{i}$. The AARB system is available on both axles and is characterized by the active torques $M_{\text {act, } r^{\circ}}$ Therefore, the gener- 
al dynamical equation of the vertical car motion is determined as:

$$
\begin{aligned}
& +k_{2}\left(\dot{Z}_{2}-\dot{Z}_{2}^{\prime}\right)+k_{3}\left(\dot{Z}_{3}-\dot{Z}_{3}^{\prime}\right)+k_{4}\left(\dot{Z}_{4}-\dot{Z}_{4}^{\prime}\right) \\
& +m_{s} a_{y} h_{R} \\
& m_{1} \ddot{Z}_{1}=-c_{1}\left(Z_{1}-Z_{1}^{\prime}\right)-k_{1}\left(\dot{Z}_{1}-\dot{Z}_{1}^{\prime}\right)+c_{t 1}\left(q_{1}-Z_{1}\right)-M_{a c t f} / 2 d \\
& m_{2} \ddot{Z}_{2}=-c_{2}\left(Z_{2}-Z_{2}^{\prime}\right)-k_{2}\left(\dot{Z}_{2}-\dot{Z}_{2}^{\prime}\right)+c_{t 2}\left(q_{2}-Z_{2}\right)-M_{\text {actr }} / 2 d \\
& m_{3} \ddot{Z}_{3}=-c_{3}\left(Z_{3}-Z_{3}^{\prime}\right)-k_{3}\left(\dot{Z}_{3}-\dot{Z}_{3}^{\prime}\right)+c_{t 3}\left(q_{3}-Z_{3}\right)+M_{a c t r} / 2 c \\
& m_{4} \ddot{Z}_{4}=-c_{4}\left(Z_{4}-Z^{\prime}{ }_{4}\right)-k_{4}\left(\dot{Z}_{4}-\dot{Z}^{\prime}{ }_{4}\right)+c_{t 4}\left(q_{4}-Z_{4}\right)+M_{\text {actf }} / 2 c \\
& Z_{1}^{\prime}=Z_{s}+d \tan \varphi-a \tan \theta \approx Z_{s}+d \varphi-a \theta \\
& Z_{2}{ }_{2}=Z_{s}+d \tan \varphi+b \tan \theta \approx Z_{s}+d \varphi+b \theta \\
& Z_{3}^{\prime}=Z_{s}-c \tan \varphi+b \tan \theta \approx Z_{s}-c \varphi+b \theta \\
& Z_{4}^{\prime}=Z_{s}-c \tan \varphi-a \tan \theta \approx Z_{s}-c \varphi-a \theta
\end{aligned}
$$$$
m_{s} \ddot{Z}_{s}=c_{1}\left(Z_{1}-Z_{1}^{\prime}\right)+c_{2}\left(Z_{2}-Z_{2}^{\prime}\right)+c_{3}\left(Z_{3}-Z_{3}^{\prime}\right)+c_{4}\left(Z_{4}-Z_{4}^{\prime}\right)+k_{1}\left(\dot{Z}_{1}-\dot{Z}_{1}^{\prime}\right)
$$$$
\left(I_{x x}+m_{s} h_{R}^{2}\right) \ddot{\phi}=-d c_{1}\left(Z_{1}-Z_{1}^{\prime}\right)-d c_{2}\left(Z_{2}-Z_{2}^{\prime}\right)+c c_{3}\left(Z_{3}-Z_{3}^{\prime}\right)+c c_{4}\left(Z_{4}-Z_{4}^{\prime}\right)
$$$$
-d k_{1}\left(\dot{Z}_{1}-\dot{Z}_{1}^{\prime}\right)-d k_{2}\left(\dot{Z}_{2}-\dot{Z}_{2}^{\prime}\right)+c k_{3}\left(\dot{Z}_{3}-\dot{Z}_{3}^{\prime}\right)+c k_{4}\left(\dot{Z}_{4}-\dot{Z}_{4}^{\prime}\right)
$$$$
\left\{\left(I_{y y}+m_{s} h_{P}^{2}\right) \ddot{\theta}=-a c_{1}\left(Z_{1}-Z_{1}^{\prime}\right)+b c_{2}\left(Z_{2}-Z_{2}^{\prime}\right)+b c_{3}\left(Z_{3}-Z^{\prime}{ }_{3}\right)-a c_{4}\left(Z_{4}-Z_{4}^{\prime}\right)\right.
$$$$
-a k_{1}\left(\dot{Z}_{1}-\dot{Z}_{1}^{\prime}\right)+b k_{2}\left(\dot{Z}_{2}-\dot{Z}_{2}^{\prime}\right)+b k_{3}\left(\dot{Z}_{3}-\dot{Z}_{3}^{\prime}\right)-a k_{4}\left(\dot{Z}_{4}-\dot{Z}_{4}^{\prime}\right)
$$

The symbols of a full car model are shown in Table 2 and their parameter values are obtained from CarSim software [18].

\section{Proposing a fully integrated model of the car}

We propose an integrated model consisting of two EH

\begin{tabular}{|c|c|c|c|}
\hline Symbols & Description & Value & Unit \\
\hline$m_{s}$ & Sprung mass & 943 & $\mathrm{~kg}$ \\
\hline$m_{i}$ & $\begin{array}{l}\text { Unsprung mass at the } i^{\text {th }} \\
\text { wheel }\end{array}$ & $50 / 75$ & $\mathrm{~kg}$ \\
\hline$k_{i}$ & $\begin{array}{l}\text { Damping ratio of the } i^{\text {th }} \\
\text { suspension system }\end{array}$ & $2290 / 1420$ & $\mathrm{Ns} / \mathrm{m}$ \\
\hline$c_{i}$ & $\begin{array}{l}\text { Stiffness coefficient of the } \\
\text { spring at the } \mathrm{ith}^{\text {th }} \text { suspen- } \\
\text { sion system }\end{array}$ & $15500 / 17000$ & $\mathrm{~N} / \mathrm{m}$ \\
\hline$C_{t i}$ & $\begin{array}{l}\text { Stiffness coefficient of the } \\
i^{\text {th }} \text { tire }\end{array}$ & 25000 & $\mathrm{~N} / \mathrm{m}$ \\
\hline a & $\begin{array}{l}\text { Distance from the CoG } \\
\text { to the centre of the front } \\
\text { wheel along longitudinal }\end{array}$ & 1,1 & $\mathrm{~m}$ \\
\hline$b$ & $\begin{array}{l}\text { Distance from the CoG } \\
\text { to the centre of the rear } \\
\text { wheel along longitudinal }\end{array}$ & 1,5 & $\mathrm{~m}$ \\
\hline$c$ & $\begin{array}{l}\text { Distance from the CoG } \\
\text { to the centre of the right } \\
\text { wheel along lateral }\end{array}$ & 0,76 & $\mathrm{~m}$ \\
\hline$d$ & $\begin{array}{l}\text { Distance from the CoG } \\
\text { to the centre of the left } \\
\text { wheel along lateral }\end{array}$ & 0,76 & $\mathrm{~m}$ \\
\hline$v$ & Speed of the vehicle & & $\mathrm{km} / \mathrm{h}$ \\
\hline$I_{x x}$ & $\begin{array}{l}\text { Roll initial moment of the } \\
\text { vehicle about the } x \text {-axis }\end{array}$ & 960 & $\mathrm{~kg} / \mathrm{m}^{2}$ \\
\hline$I_{y y}$ & $\begin{array}{l}\text { Pitch initial moment of the } \\
\text { vehicle about the } y \text {-axis }\end{array}$ & 720 & $\mathrm{~kg} / \mathrm{m}^{2}$ \\
\hline$I_{z z}$ & $\begin{array}{l}\text { Yaw initial moment of the } \\
\text { vehicle about the z-axis }\end{array}$ & 4520 & $\mathrm{~kg} / \mathrm{m}^{2}$ \\
\hline$C_{f}$ & $\begin{array}{l}\text { Tire cornering stiffness at } \\
\text { the front axle }\end{array}$ & 18000 & $\mathrm{~N} / \mathrm{m}$ \\
\hline$C_{r}$ & $\begin{array}{l}\text { Tire cornering stiffness at } \\
\text { the rear axle }\end{array}$ & 18000 & $\mathrm{~N} / \mathrm{m}$ \\
\hline$g$ & Gravity of Earth & 9,81 & $\mathrm{~m} / \mathrm{s}^{2}$ \\
\hline$h_{p}$ & $\begin{array}{c}\text { Distance from the centre } \\
\text { of the chassis to the pitch } \\
\text { axis }\end{array}$ & 0,1 & $\mathrm{~m}$ \\
\hline$h_{r}$ & $\begin{array}{c}\text { Distance from the centre } \\
\text { of the chassis to the roll } \\
\text { axis }\end{array}$ & 0,2 & $\mathrm{~m}$ \\
\hline
\end{tabular}
actuators and a full car model. In which, the AARB system is located on both axles and controlled by the input currents $u_{f r}$. The excitation sources include the steering angle and the road surface at the four wheels. Thus the dynamical equation of the whole system is determined as follows:

$$
\begin{aligned}
& m_{s} \ddot{Z}_{s}=c_{1}\left(Z_{1}-Z_{1}^{\prime}\right)+c_{2}\left(Z_{2}-Z_{2}^{\prime}\right)+c_{3}\left(Z_{3}-Z_{3}^{\prime}\right)+c_{4}\left(Z_{4}-Z_{4}^{\prime}\right)+k_{1}\left(\dot{Z}_{1}-\dot{Z}_{1}^{\prime}\right) \\
& +k_{2}\left(\dot{Z}_{2}-\dot{Z}_{2}^{\prime}\right)+k_{3}\left(\dot{Z}_{3}-\dot{Z}_{3}^{\prime}\right)+k_{4}\left(\dot{Z}_{4}-\dot{Z}_{4}^{\prime}\right) \\
& \left(I_{x x}+m_{s} h_{R}{ }^{2}\right) \ddot{\phi}=-d c_{1}\left(Z_{1}-Z_{1}^{\prime}\right)-d c_{2}\left(Z_{2}-Z_{2}^{\prime}\right)+c c_{3}\left(Z_{3}-Z_{3}^{\prime}\right)+c c_{4}\left(Z_{4}-Z_{4}^{\prime}\right) \\
& -d k_{1}\left(\dot{Z}_{1}-\dot{Z}_{1}^{\prime}\right)-d k_{2}\left(\dot{Z}_{2}-\dot{Z}_{2}^{\prime}\right)+c k_{3}\left(\dot{Z}_{3}-\dot{Z}_{3}^{\prime}\right)+c k_{4}\left(\dot{Z}_{4}-\dot{Z}_{4}^{\prime}\right)+m_{s} a_{y} h_{R} \\
& \left(I_{y y}+m_{s} h_{P}{ }^{2}\right) \ddot{\theta}=-a c_{1}\left(Z_{1}-Z_{1}^{\prime}\right)+b c_{2}\left(Z_{2}-Z_{2}^{\prime}\right)+b c_{3}\left(Z_{3}-Z_{3}^{\prime}\right)-a c_{4}\left(Z_{4}-Z_{4}^{\prime}\right) \\
& -a k_{1}\left(\dot{Z}_{1}-\dot{Z}_{1}^{\prime}\right)+b k_{2}\left(\dot{Z}_{2}-\dot{Z}_{2}^{\prime}\right)+b k_{3}\left(\dot{Z}_{3}-\dot{Z}_{3}^{\prime}\right)-a k_{4}\left(\dot{Z}_{4}-\dot{Z}_{4}^{\prime}\right) \\
& m_{1} \ddot{Z}_{1}=-c_{1}\left(Z_{1}-Z_{1}^{\prime}\right)-k_{1}\left(\dot{Z}_{1}-\dot{Z}_{1}^{\prime}\right)+c_{t 1}\left(q_{1}-Z_{1}\right)_{1}-A_{v 1} \mathrm{a}_{a r n} / 2 d \\
& m_{2} \ddot{Z}_{2}=-c_{2}\left(Z_{2}-Z_{2}^{\prime}\right)-k_{2}\left(\dot{Z}_{2}-\dot{Z}_{2}^{\prime}\right)+c_{t 2}\left(q_{2}-Z_{2}\right)_{2}-A_{v 2} \mathrm{a}_{a r n} / 2 d \\
& m_{3} \ddot{Z}_{3}=-c_{3}\left(Z_{3}-Z_{3}^{\prime}\right)-k_{3}\left(\dot{Z}_{3}-\dot{Z}_{3}^{\prime}\right)+c_{t 3}\left(q_{3}-Z_{3}\right)+A_{v 2} \mathrm{a}_{a r n} / 2 c \\
& m_{4} \ddot{Z}_{4}=-c_{4}\left(Z_{4}-Z_{4}^{\prime}\right)-k_{4}\left(\dot{Z}_{4}-\dot{Z}_{4}^{\prime}\right)+c_{t 4}\left(q_{4}-Z_{4}\right)+A_{v 1} \mathrm{a}_{a r n} / 2 c \\
& \ddot{X}_{v 1}=K_{v} u_{1} w_{v}^{2}-2 D_{v} \ddot{X}_{v 1} w_{v}-X_{v 1} w_{v}^{2} \\
& \left\{\ddot{P}_{L 1}=\frac{4 \beta_{E}}{V_{t}} K_{q} X_{v 1}-\frac{4 \beta_{E}}{V_{t}} P_{L 1}\left(K_{c}+c_{l 2}\right)-\frac{4 \beta_{E}}{V_{t}} V_{p} \vartheta_{1}+\frac{4 \beta_{E}}{V_{t}} c_{l 1} \dot{\vartheta}_{1}\right. \\
& \ddot{\vartheta}_{1}=\frac{-d_{a} \dot{\vartheta}_{1}}{J}+\frac{V_{p} P_{L 1}}{J}+\frac{M_{e c t 1}}{J} \\
& \ddot{X}_{v 2}=K_{v} u_{2} w_{v}^{2}-2 D_{v} \dot{X}_{v 2} w_{v}-X_{v 2} w_{v}^{2} \\
& \dot{P}_{L 2}=\frac{4 \beta_{E}}{V_{t}} K_{q} X_{v 2}-\frac{4 \beta_{E}}{V_{t}} P_{L 2}\left(K_{c}+c_{l 2}\right)-\frac{4 \beta_{E}}{V_{t}} V_{p} \vartheta_{2}+\frac{4 \beta_{E}}{V_{t}} c_{l 1} \dot{\vartheta}_{2} \\
& \ddot{\vartheta}_{2}=\frac{-d_{a} \dot{\vartheta}_{2}}{J}+\frac{V_{p} P_{L 2}}{J}+\frac{M_{e c t 2}}{J} \\
& m v \dot{\beta}+\left(m v+\frac{a C_{f}-b C_{r}}{v}\right) \dot{\psi}=C_{f} \delta-\left(C_{f}+C_{r}\right) \beta \\
& I_{z z} \ddot{\psi}=a C_{f} \delta-\left(a C_{f}-b C_{r}\right) \beta-\frac{\left(a^{2} C_{f}+b^{2} C_{r}\right)}{v} \dot{\psi}
\end{aligned}
$$

Table 2: The symbols and parameters of a full car model

The dynamical equation (11) is written as the state-space form of the Linear Time Invariant (LTI) model as follows:

$\left\{\begin{array}{l}\dot{X}=A X+B_{1} W+B_{2} U \\ Y=C X+D_{1} W+D_{2} U\end{array}\right.$

Where the state vector is chosen as

$$
X=\left[\begin{array}{cccccccccccccc}
Z_{s} & \phi & \theta & Z_{1} & Z_{2} & Z_{3} & Z_{4} & \dot{Z}_{s} & \dot{\phi} & \dot{\theta} & \dot{Z}_{1} & \dot{Z}_{2} & \dot{Z}_{3} & \dot{Z}_{4} \\
X_{v 1} & \dot{X}_{v 1} & P_{L 1} & \vartheta_{1} & \dot{\vartheta}_{1} & X_{v 2} & \dot{X}_{v 2} & P_{L 2} & \vartheta_{2} & \dot{\vartheta}_{2} & \beta & \dot{\psi}
\end{array}\right]^{T}
$$

the disturbance input: $W=\left[q_{1} q_{2} q_{3} q_{4} \delta\right]^{T}$; the control input: $U=\left[u_{1} u_{2}\right]^{T}$; the output $Y=X . A, B_{1}, B_{2}, C, D_{1}, D_{2}$ are the corresponding matrices and presented in the appen- 
dix. From the representation of the dynamical equation as in (12), the system's stability and controllability are guaranteed.

\section{LQR ACTIVE ANTI-ROLL BAR CONTROLLER DESIGN}

\section{Performance criteria}

The statistical studies have shown that sudden braking, sudden steering in emergency situations and side wind gusts are three of the main factors that cause a car's rollover phenomenon [2]. In all the above factors, the sprung mass roll angle is often existed and creates an instability moment of the car. Therefore, the AARB system has to act on the sprung mass with an active torque to bring it back to a balanced position. Accurate determination of rollover properties is not a simple task. Most current studies consider when the wheels lift off from the road as the time when cars begin to lose roll stability. Therefore, the roll stability of cars is assessed through the following two main criteria [2, 19]:

- The maximum absolute value of the sprung mass roll angle does not exceed 6-8 degrees: $|\phi|_{\max } \leq 6-8[\mathrm{deg}]$. The smaller the absolute value of this angle, the greater the roll stability of cars. This has the effect of avoiding the risk of vehicle rollover. Therefore, the absolute value of this angle is as small as possible.

- When the value of the interaction force between the wheels and the road surface (the tire force in the $z$ direction $-F_{z i}$ ) is less sensitive to the excitation sources the better. This force is always fluctuating around the static load, the smaller the dynamic value, the lower the ability to separate the wheel from the road surface. However, in practice it is very difficult to measure accurately this force. Due to the tire force in the $z$ direction being linearly dependent on the unsprung mass vertical displacement $\left(Z_{j}\right)$, thus it is common to choose this displacement instead of the interaction force in the controller designs.

In the following sections, the above two criteria are used both to design the controller and to assess the effectiveness of the AARB system.

\section{LQR controller synthesis for an AARB system}

In this study, the author uses one of the well-known advanced control methods, the LQR (Linear Quadratic Regulator) optimal control method, to design the controller for the AARB system to improve the car roll stability. The LTI model is shown in Equation (12). It should be noted that the matrix $B$ used in this section is derived from the traditional form of the state space representation, thus $B=\left[B_{1}, B_{2}\right]$. For $L Q R$ controller synthesis, we can assume that all the variables of the state vector can be measured or estimated. Therefore, the state feedback control law is defined as $[2,20]$ :

$u=-K x$ where $K=R^{-1} B^{T} P$ is the state feedback gain matrix. In which, the matrix $P$ is defined from the algebraic Riccati equation:

$$
A^{T} P+A P+Q-P B R^{-1} B^{T} P=0
$$

Therefore, the control input $u$ will have the effect of minimizing some performance index $-J$, which is generally represented as follows [16]:

$$
J=\int_{0}^{\infty}\left(x^{T} Q x+u^{T} R u+2 x^{T} N u\right) d t
$$

The main goal of the LQR controller design is to optimize the car roll stability. The sprung mass roll angle and its velocity, the vertical displacement of the four unsprung masses and the interaction forces between the wheels and the road surface are the parameters that directly affect the vehicle roll stability. Therefore, the parameters defined above should be optimized. The performance index $\mathrm{J}$ of the LQR controller for this system is selected as follows:

$$
J=\int_{0}^{\infty}\left(\begin{array}{l}
\rho_{1} Z_{s}^{2}+\rho_{2} \phi^{2}+\rho_{3} \theta^{2}+\rho_{4} Z_{1}^{2}+\rho_{5} Z_{2}^{2}+\rho_{6} Z_{3}^{2}+\rho_{7} Z_{4}^{2} \\
+\rho_{8} \dot{Z}_{s}^{2}+\rho_{9} \dot{\phi}^{2}+\rho_{10} \dot{\theta}^{2}+\rho_{11} \dot{Z}_{1}^{2}+\rho_{12} \dot{Z}_{2}^{2}+\rho_{13} \dot{Z}_{3}^{2}+\rho_{14} \dot{Z}_{4}^{2} \\
+\rho_{15} X_{v 1}^{2}+\rho_{16} \dot{X}_{v 1}^{2}+\rho_{17} P_{L 1}^{2}+\rho_{18} \vartheta_{1}^{2}+\rho_{19} \dot{\vartheta}_{1}^{2}+\rho_{20} X_{v 2}^{2}+\rho_{21} \dot{X}_{v 2}^{2} \\
+\rho_{22} P_{L 2}^{2}+\rho_{23} \vartheta_{2}^{2}+\rho_{24} \dot{\vartheta}_{2}^{2}+\rho_{25} \beta^{2}+\rho_{26} \dot{\psi}^{2}+\rho_{\mathrm{if}} i_{f}^{2}+\rho_{\mathrm{ir}} i_{r}^{2}
\end{array}\right) d t
$$

where $\rho_{1}, \rho_{2}, \rho_{3}, \ldots, \rho_{26}, \rho_{\mathrm{ip}}, \rho_{\mathrm{ir}}$ are defined as the weighting parameters of the performance index J. Depending on the choice of $\rho_{i}$, it is possible to process a large set of different properties such as enhancing the roll stability or avoiding actuator saturation. The weighting parameters in this case have the following selected values:

$\rho_{1}=\rho_{2}=10^{5}, \rho_{3}=10^{9}, \rho_{4}=\rho_{5}=\rho_{6}=\rho_{7}=10^{8}$,

$\rho_{8}, \rho_{9}, \rho_{10}, \ldots, \rho_{26}=1, \rho_{\mathrm{if}}, \rho_{\mathrm{ir}}=1$.

From equations (15) and (16), the matrix $Q$ is defined as an unit matrix with 26 diagonal elements being $\rho_{1} \ldots \rho_{16}$, while the matrix $\mathrm{R}$ has 2 diagonal elements of $\rho_{\mathrm{if}}, \rho_{\mathrm{ir}}$.

Remarks: The choice of the performance index $\mathrm{J}$ setting as above is considered to be the simplest way to define the $Q, R$ matrices in (15). Due to the characteristics of this control goal, the above selection is very reasonable. However, another approach can be developed to achieve other control targets.

\section{SIMULATION RESULTS ANALYSIS IN THE FREQUENCY DOMAIN}

In this part, the simulation results of the integrated full car model using the two EH actuators with a state feedback LQR controller are evaluated in the frequency domain. The car speed is kept constant at $70 \mathrm{~km} / \mathrm{h}$. The total weight and the center of gravity of cars are usually not large, thus the rollover phenomenon usually occurs when the car turns or when the vehicle steers rapidly to avoid obstacles at high speed. Therefore, the influence of the sudden steering maneuvers and in particular the steering angle, is generally an important disturbance input when studying the roll stability characteristics of cars. 
Here the author uses the transfer function magnitude (Bode diagram) from the disturbance(steering angle) to the evaluation criteria such as the sprung mass roll angle and its velocity (roll rate), the vertical unsprung masses displacement, the interaction force of the four wheels with the road surface. The frequency range is surveyed up to $4 \mathrm{rad} / \mathrm{s}$, as this region characterizes the driver's bandwidth [2, 12].

Figure 3 shows the response in the frequency domain of the sprung mass roll angle $\phi(a)$, the roll rate $\dot{\phi}(b)$, the vertical displacements of the left-front wheel $Z_{1}$ (c) and the left-rear wheel $Z_{2}(d)$. It indicates that the car using proposed LQR AARB system has significantly reduced the transfer function magnitude when compared to a car using a passive ARB system, specifically: the sprung mass roll angle and its velocity have been reduced by

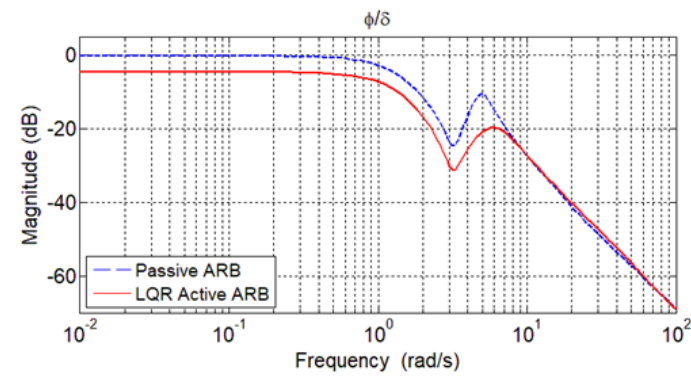

(a)

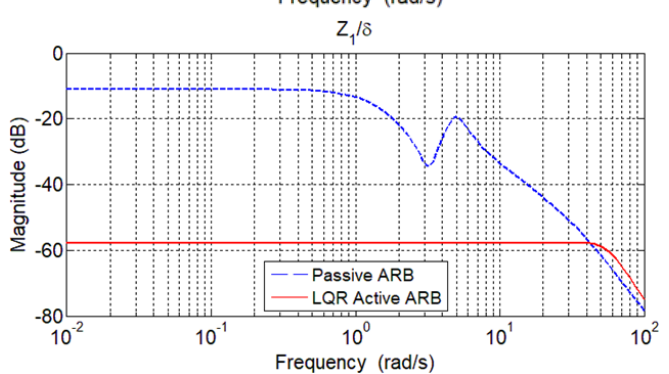

about $5 \mathrm{~dB}$, the vertical displacement of the wheels have decreased by about $30 \mathrm{~dB}$.

Another very important parameter related to the assessment of the roll stability of cars is the interaction forces between the wheels and the road surface. When these forces are smaller, the car movement is safer, because the risk of separating the wheels from the road surface decreases. Figure 4 shows the response in the frequency domain of the interaction force of the left-front wheel (a), the left-rear wheel (c), the right-rear wheel (d) and the right- front wheel (b) to the road surface. It shows that the transfer function magnitude from the steering angle to the interaction force of the front wheels decreased by about $28 \mathrm{~dB}$, while the reduction for the rear wheels is about $30 \mathrm{~dB}$ lower than the car using a passive ARB sys-
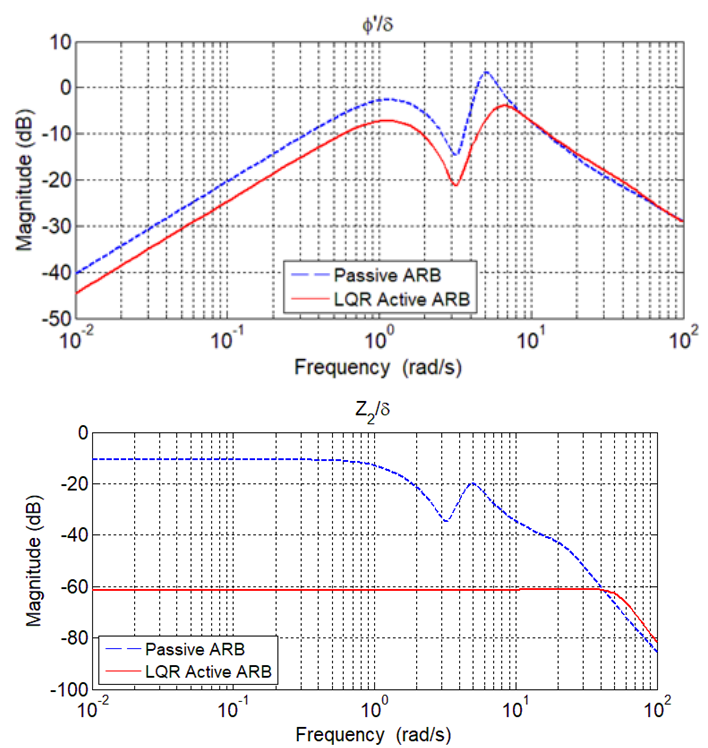

Figure 3: Transfer function magnitude from the steering angle to a) the sprung mass roll angle, b) the roll rate, the vertical displacement ofc) the left-front wheel and d) the left-rear wheel

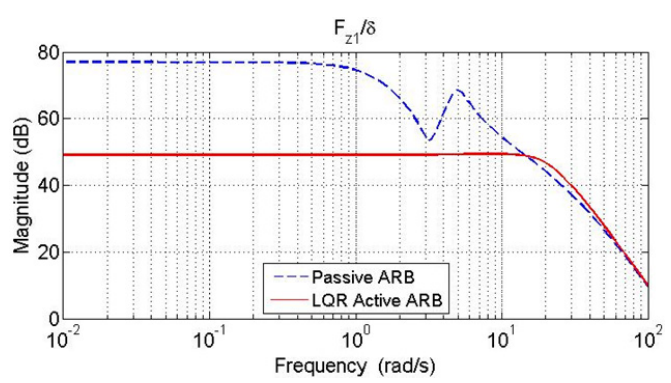

(a)
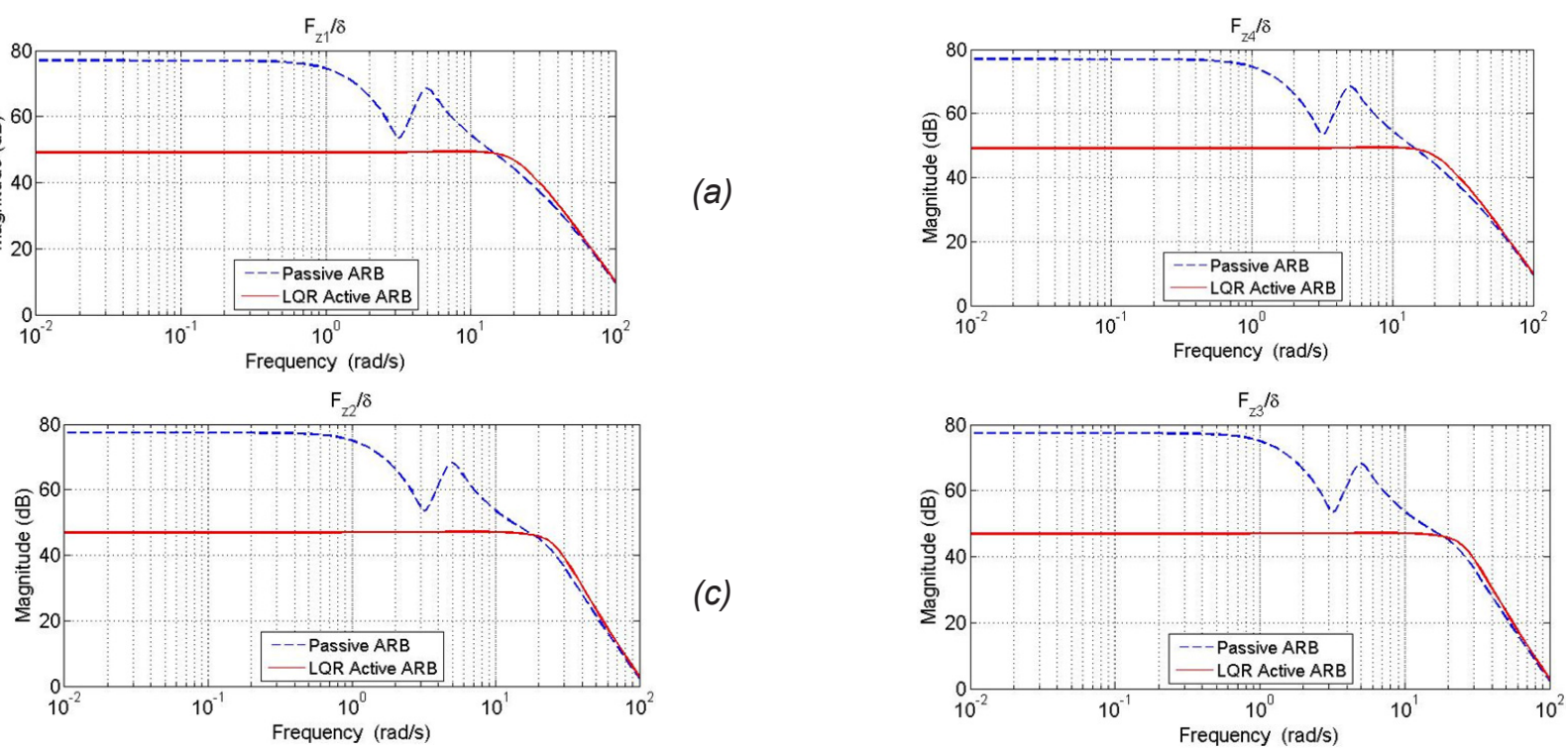

Figure 4: Transfer function magnitude from the steering angle to the interaction force of the four wheels: left-front (a), left-rear (c), right-front (b), right-rear (d) 
tem. It indicates that the LQR AARB system significantly increased the car's motion safety.

Table 3 shows clearly the decrease of the transfer function magnitude at $1 \mathrm{rad} / \mathrm{s}$. It is important to notice that for the AARB system with steering disturbance, the frequency range of interest is lower than $4 \mathrm{rad} / \mathrm{s}[4,12,21]$. Thus, the evaluation criteria have decreased significantly when compared to the car using the passive suspension system.

Figure 5 shows the transfer function magnitude from the steering angle to the input currents of the active anti-roll bar system at the two axles. Because the weighting parameters $\rho_{\mathrm{if}}, \rho_{\mathrm{ir}}=1$ thus the controller does not focus too much on reducing the magnitude of the currents.

Conducting the same survey with different speeds, the response in the frequency domain shows that using the LQR AARB system has significantly improved the roll stability, when compared with the conventional passive system. This allows to prevent the rollover situation in emergencies, and demonstrates the outstanding advantages of the control design approach.

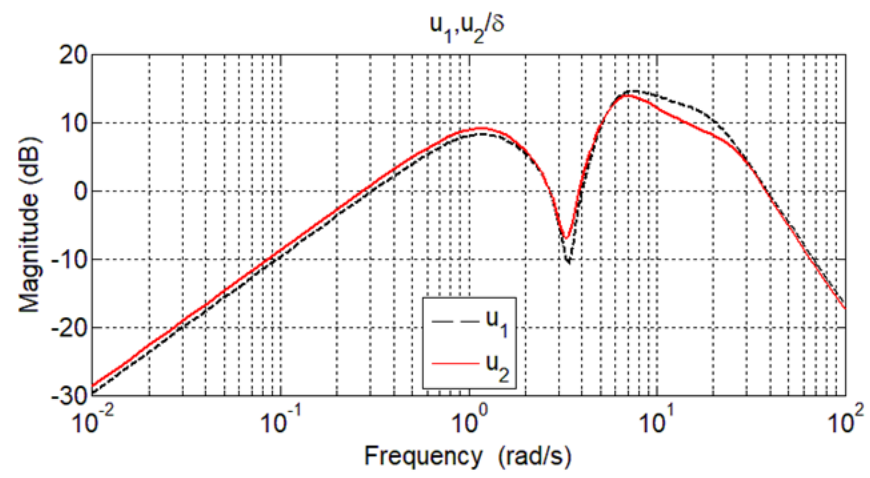

Figure 5: Transfer function magnitude from the steering angle to the control inputs

\section{VALIDATION BY NONLINEAR CAR MODEL OF CARSIM ${ }^{\circledR}$ SOFTWARE}

This section is devoted to the validation of the LQR AARB control system using the nonlinear car model from CarSim simulation software. This software has many advantages and it is proven to be nearly equivalent to actual cars. CarSim can provide the most accurate and efficient methods for simulating car's properties. This popular software is an effective tool for developing active (semi-active) control systems, analyzing vehicle dynamics, calculating vehicle performance characteristics and active safety systems.

To evaluate the proposed LQR controller for the AARB system with a nonlinear car model, the author sets up a co-simulation program between $\mathrm{CarSim}^{\circledR}$ and Matlab ${ }^{\circledR}$ softwares as described in Figure 6. From CarSim software, a high-order nonlinear car model is exported as an $S$ functions in Simulink. Meanwhile, in the Matlab/Simulink environment we can build directly the controller and the actuators.

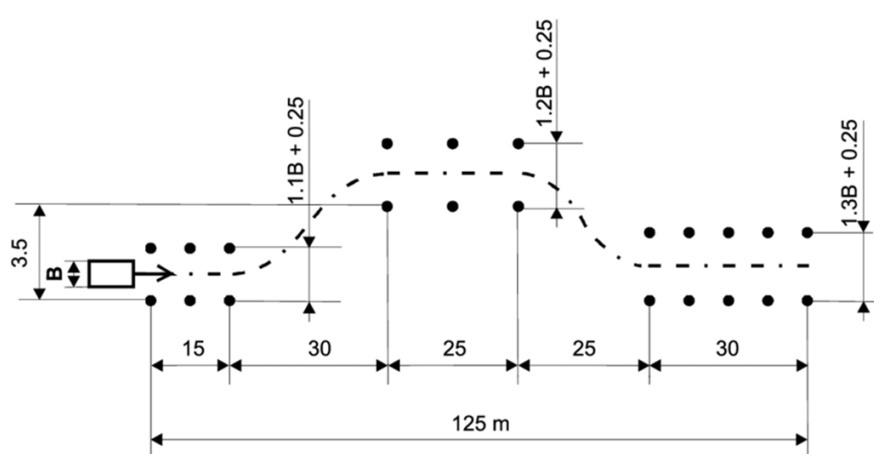

Figure 7: Trajectory of the DLC maneuver according to Standard No. ISO 3888 [23]

In the CarSim software, the interaction force $\left(F_{z}\right)$ between the wheels and the road surface can be obtained easily. These forces will therefore be used to assess the sys-

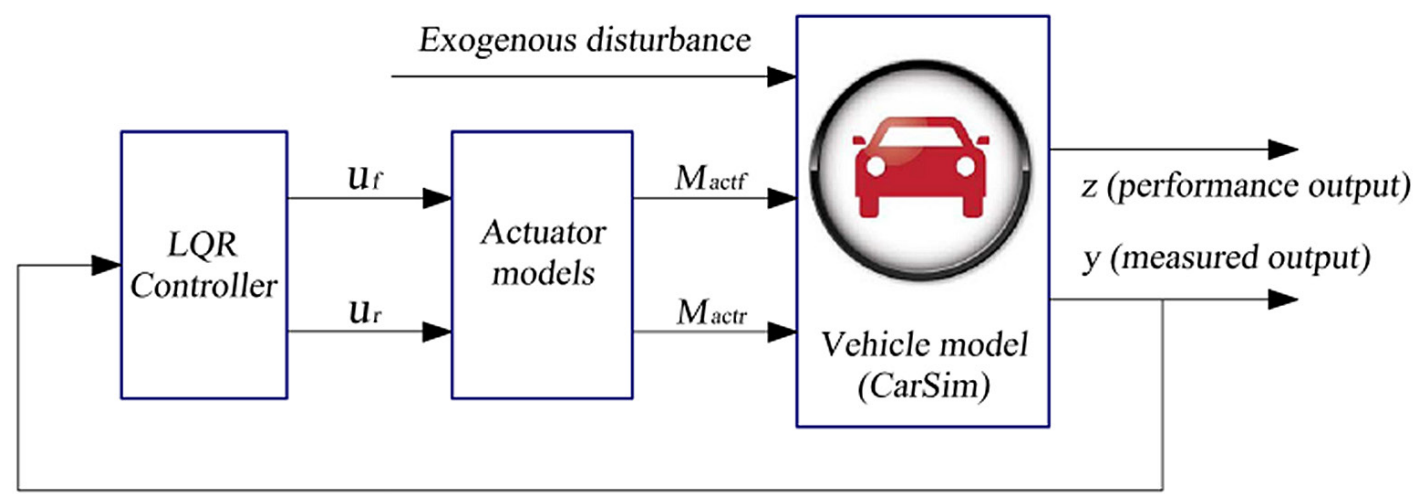

Figure 6: Cosimulation diagram: CarSim $^{\circledR}-$ Matlab $^{\circledR}$

Table 3: Reduction of transfer function magnitude compared to the passive case

\begin{tabular}{|c|c|c|c|c|c|c|c|c|}
\hline $\begin{array}{c}\text { Transfer } \\
\text { functions }\end{array}$ & $\frac{\phi}{\delta}$ & $\frac{\dot{\phi}}{\delta}$ & $\frac{Z_{1}}{\delta}$ & $\frac{Z_{2}}{\delta}$ & $\frac{F_{z 1}}{\delta}$ & $\frac{F_{z 2}}{\delta}$ & $\frac{F_{z 3}}{\delta}$ & $\frac{F_{z 4}}{\delta}$ \\
\hline $\begin{array}{c}\text { Reduction } \\
(\mathrm{dB})\end{array}$ & 4.3 & 4.4 & 27.8 & 30.5 & 27.8 & 30.4 & 27.8 & 30.4 \\
\hline
\end{tabular}


tem's ability to enhance the car's roll stability. When the value of $\mathrm{Fz}$ is positive, the wheel and the road surface remain in contact, when the value of $F_{z}$ is zero, the wheel separates from the road surface, thus the car rollover phenomenon is considered to start occurring. We use the scenario of a car in a Double Lane Change (DLC) situation for avoiding obstacles as shown in Figure 7. To ensure the car's trajectory with the AARB system and the passive system in the DLC maneuvers, the steering angle $\delta$ is changed automatically thanks to the closedloop driver model $[4,22]$. Hence these angles are shown in Figure 8.

Figure 9 describes the response in the time domain of the sprung mass roll angle when the car's speed is 100 $\mathrm{km} / \mathrm{h}$. It shows that with the car using the AARB system, the maximum absolute value of the roll angle decreases about $29 \%$, when compared to the car using a passive

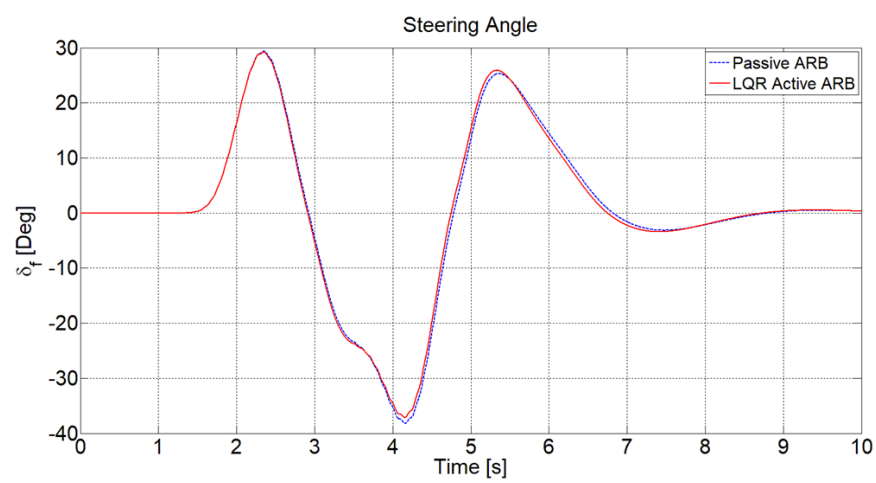

Figure 8: Steering angles in the DLC maneuver ISO 3888

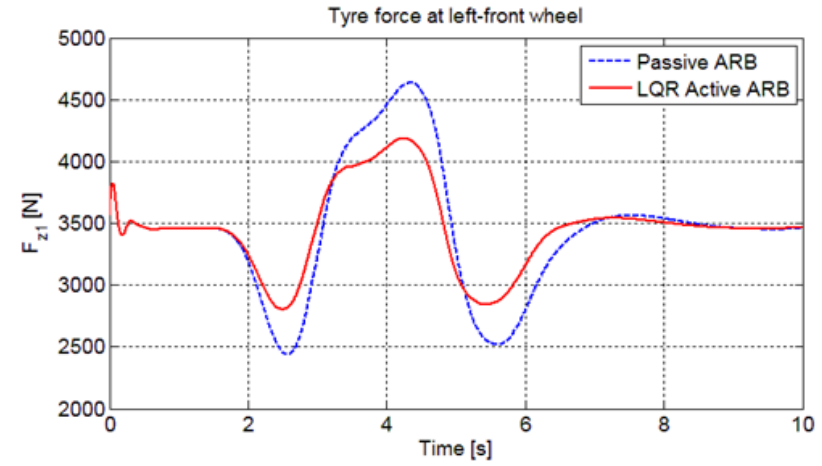

(a)

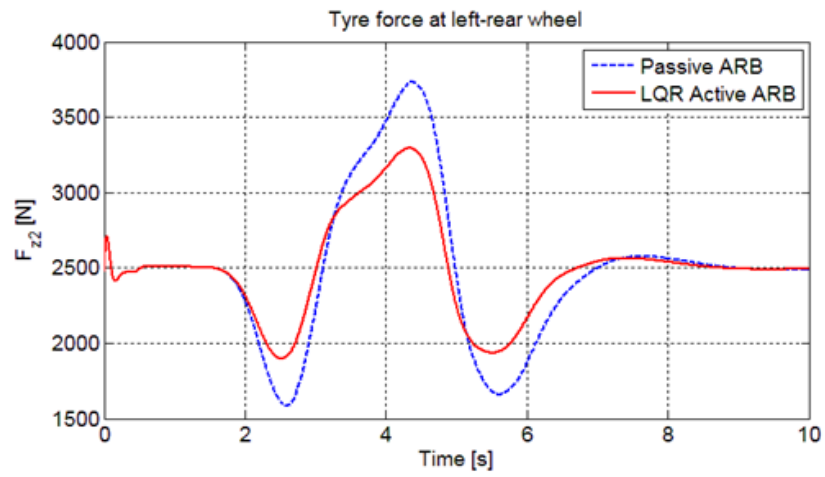

suspension system.

Figure 10 describes the time response of the vertical tire forces in the $z$ direction (between the wheels and the road surface). It turns out that the car with the LQR AARB system maintained a significant degree of stability of these interaction forces in the comparison with the car using the passive ARB system. Thus, it can be seen that, with the AARB system, the sprung mass roll angle, the interaction forces are all reduced (oscillating around the equilibrium position), which means that the car roll stability is increased to avoid the rollover phenomenon.

To overall assess the roll stability of the car using LQR AARB system, the car is investigated with the different speeds from $60 \mathrm{~km} / \mathrm{h}$ to $160 \mathrm{~km} / \mathrm{h}$. The Root Mean Square (RMS) as in Equation (17) is used for the performance criteria of the sprung mass roll angle and the

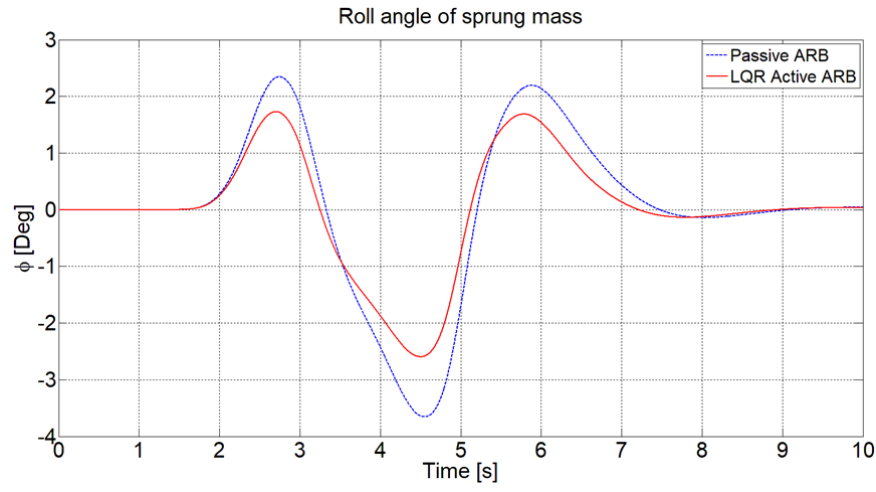

Figure 9: Sprung mass roll angle in the DLC maneuver
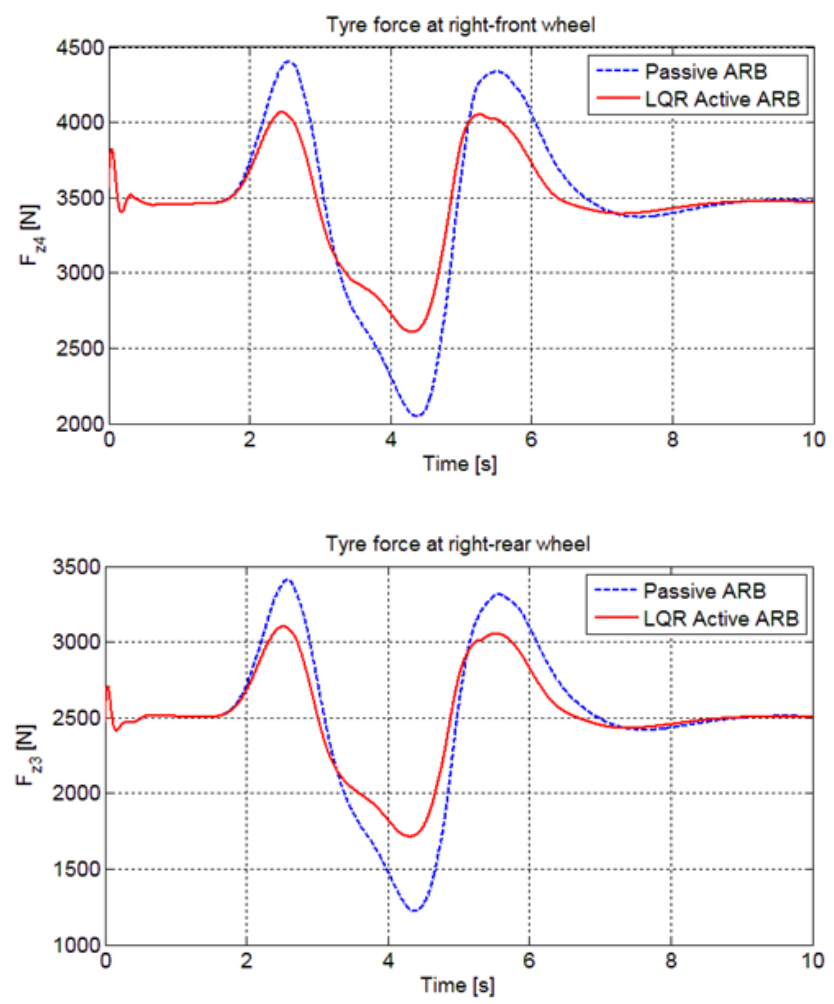

(d)

Figure 10: Tire forces in the DLC maneuvers 
Table 4: Comparison of the RMS value of the sprung mass roll angle

\begin{tabular}{|c|c|c|c|c|c|c|}
\hline $\mathrm{V}(\mathrm{km} / \mathrm{h})$ & 60 & 80 & 100 & 120 & 140 & 160 \\
\hline Passive ARB & 0.9312 & 1.1680 & 1.3934 & 1.5956 & 1.7020 & 1.7083 \\
\hline LQR AARB & 0.6746 & 0.8434 & 1.0100 & 1.1648 & 1.2534 & 1.2600 \\
\hline Reduction $(\%)$ & 27.6 & 27.8 & 27.5 & 27.0 & 26.4 & 26.2 \\
\hline
\end{tabular}

interaction forces [2]. Table 4 summarizes the RMS value of the sprung mass roll angle. This result indicates that with the car speed from $60 \mathrm{~km} / \mathrm{h}$ to $160 \mathrm{~km} / \mathrm{h}$, the decrease of the RMS is about $26 \%$ to $28 \%$ when using the LQR AARB system [2].

$$
R M S(y)=\sqrt{\frac{1}{T} \int_{0}^{T} y^{2}(t) d t}
$$

where $T$ is the period of repetition, $y(t)$ is the symbol representing the signals of interest.

It is also important to survey the RMS value of the interaction forces when the car is moving at different speeds. The reduction of RMS of the car using the LQR active anti-roll bar system compared to using the passive system is listed in Table 5. It is shown that the car using the LQR AARB system has helped the interaction forces being more stability of $30 \%$ than the passive system. This reduction is relatively stable even at the middle speed of $60 \mathrm{~km} / \mathrm{h}$ or at the high speed of $160 \mathrm{~km} / \mathrm{h}$.

Table 5: Reduction of RMS value of the interaction forces in the different speeds

\begin{tabular}{|c|c|c|c|c|c|c|}
\hline $\mathrm{V}(\mathrm{km} / \mathrm{h})$ & 60 & 80 & 100 & 120 & 140 & 160 \\
\hline RMS $\left(\mathrm{F}_{\mathrm{z} 1}\right)(\%)$ & 37.9 & 37.9 & 36.5 & 34.6 & 33.3 & 32.7 \\
\hline RMS $\left(\mathrm{F}_{\mathrm{z} 4}\right)(\%)$ & 38.0 & 38.5 & 37.2 & 35.1 & 34.1 & 33.3 \\
\hline RMS $\left(\mathrm{F}_{z 2}\right)(\%)$ & 34.9 & 34.9 & 34.2 & 33.4 & 33.2 & 32.8 \\
\hline RMS $\left(\mathrm{F}_{z 3}\right)(\%)$ & 34.9 & 35.3 & 35.3 & 35.1 & 34.8 & 34.3 \\
\hline
\end{tabular}

\section{CONCLUSION}

This paper presents building an integrated model that includes a full car model: lateral, longitudinal and vertical motions with the EH actuators on the two axles. The control signals are the input current supplied to the actuators, while the excitation sources are the steering angle from the driver and the roughness profile from the road surface. To further enhance the car's roll stability to prevent the rollover phenomenon, an optimal LQR controller is constructed based on all variables of the state vector. The evaluation in the frequency domain are shown by the transfer function magnitude from the steering angle to the sprung mass roll angle, vertical displacement of the unsprung masses and the interaction force between the wheels and the road surface. The value of the transfer function magnitude of the survey signals has decreased significantly in the frequency range of interest. The validation with the car's nonlinear model from CarSim soft- ware clearly shows the outstanding advantage of this design solution in preventing a car rollover situation.

In the future, the observer design will be performed on the proposed car model to further evaluate the system's characteristics. The $H_{2} / H_{\infty}$ state feedback control for the LTI and LPV systems are also interesting topics to consider.

\section{REFERENCES}

1. M. Kurhe Nikhil, Dheeraj Hari Daspute. (2018). Dynamic analysis of anti roll bar. Materials today: proceedings, vol. 5 , no. 5 , p. 12490-12498, https://doi. org/10.1016/j.matpr.2018.02.230

2. Van Tan Vu, Olivier Sename, Luc Dugard, Peter Gaspar. (2017). Enhancing roll stability of heavy vehicle by LQR active anti-roll bar control using electronic servovalve hydraulic actuators. Vehicle System Dynamics, vol. 55, no. 9, p. 1405-1429, https://doi.org/ 10.1080/00423114.2017.1317822

3. Sampson David, David Cebon. (2003). Active Roll Control of Single Unit Heavy Road Vehicles. Vehicle System Dynamics, vol. 40, no. 4, p. 229-270, DOI: 10.1076/vesd.40.2.229.16540

4. Van Tan Vu, Olivier Sename, Luc Dugard, Peter Gaspar. (2019). An Investigation into the Oil Leakage Effect Inside the Electronic Servo-valve for an $\mathrm{H}_{\infty} / \mathrm{LPV}$ Active Anti-roll Bar System. International Journal of Control, Automation and Systems, vol. 17, p. 2917-2928, http://dx.doi.org/10.1007/s12555019-0060-2

5. S. Yim, K. Jeon, K. Yi. (2012). An investigation into vehicle rollover prevention by coordinated control of active anti-roll bar and electronic stability program. International Journal of Control, Automation and Systems, vol. 10, no. 2, p. $275-287,2012$. https:// doi.org/10.1007/s12555-012-0208-9

6. K. Yamamoto, H. Nishimura. (2011). Control system design of electric power steering for a full vehicle model with active stabilizer. Journal of System Design and Dynamics, vol 5, no. 5, p. 789-804, https:// doi.org/10.1299/jsmemovic.2010._3A14-1_

7. Mohamed Krid, Faiz Benamar. (2011). Design and control of an active anti-roll system for a fast rover. IEEE International Conference on Intelligent Robots and Systems, San Francisco, CA, USA. DOI: 10.1109/IROS.2011.6094963 
8. Milos Maljkovic, Ivan Blagojevic, Vladimir Popovic, Dragan Stamenkovic. (2018). Impact of the damper characteristics on the behavior of suspension system and the whole vehicle. Journal of Applied Engineering Science, 2018, vol. 16, br. 3, str. 349-357, Doi:10.5937/jaes16-17342

9. Vesna Spasojevic Brkic, Zorica Veljkovic, Ahmed Ali Essdai, Aleksandar Brkic. (2019). Differences in anthropometric measurements between Libyan and Serbian passenger car drivers and crane operators. Journal of Applied Engineering Science, 2019, vol. 17, br. 1, str. 1-7, Doi:10.5937/jaes17-19969

10. Noraishikin Zulkarnain, Fitrian Imaduddin, Hairi Zamzuri, Saiful Amri Mazlan. (2012). Application of an Active Anti-roll Bar System for Enhancing Vehicle Ride and Handling. IEEE Colloquium on Humanities, Science \& Engineering Research (CHUSER 2012), December 3-4, 2012, Kota Kinabalu, Sabah, Malaysia, DOI: 10.1109/CHUSER.2012.6504321

11. N. Zulkarnain,H. Zamzuri, Y. M. Sam, S. A. Mazlan, S. M. H. F. Zainal. (2014). Improving Vehicle Ride and Handling Using LQG CNF Fusion Control Strategy for an Active Antiroll Bar System. Abstract and Applied Analysis, http://dx.doi.org/10.1155/2014/698195

12. Balazs Varga, Balazs Nemeth, Peter Gaspar. (2015). Design of Anti-Roll Bar Systems Based on Hierarchical Control" Journal of Mechanical Engineering, vol. 61 , no. 6 , p. $374-382$, https://doi.org/10.5545/svjme.2014.2224

13. Balazs Varga, Balazs Nameth, Peter Gaspar (2013). Control design of anti-roll bar actuator based on constrained LQ method IEEE 14th International Symposium on Computational Intelligence and Informatics (CINTI), Budapest, Hungary, DOI: 10.1109/ CINTI.2013.6705219

14. Balazs Varga, Balazs Nemeth, Peter Gaspar. (2014). Hierarchical Design of Electro-Hydraulic Actuator Control for Vehicle Dynamic Purposes. European Control Conference (ECC), Strasbourg, France, DOI: 10.1109/ECC.2014.6862427

15. S. Gosselin-Brissona, M. Bouazaraa, M.J. Richardb. (2009). Design of an active anti-roll bar for off-road vehicles. Shock and Vibration, vol. 16, p. 155-174, https://doi.org/10.3233/SAV-2009-0459

16. Van Tan Vu, Olivier Sename, Luc Dugard, Peter Gaspar. (2016). Active anti-roll bar control using electronic servo valve hydraulic damper on single unit heavy vehicle. 8th IFAC International Symposium on Advances in Automotive Control (AAC 2016), Jun 2016, Norrkoping, Sweden. p. 418-425, https://doi. org/10.1016/j.ifacol.2016.08.062, (hal-01314529)
17. Andras Mihaly, Peter Gaspar, Hakan Basar Gan. (2019). Maximizing autonomous in-wheel electric vehicle battery state of charge with optimal control allocation. 18th European Control Conference (ECC), Napoli, Italy, DOI: 10.23919/ECC.2019.8796288

18. Tudon-Martinez, J., Lozoya-Santos, J., and Morales-Menendez, R. (2012). Efficiency of On-Off Semiactive Suspensions in a Pick-up Truck. SAE Int. J. Commer. Veh, vol. 5, no. 1, p. 333-342, https://doi. org/10.4271/2012-01-0979

19. T. J. Yuen, R.Rahizar, Z. A.M. Azman, A. Anuar, D.Afandi. (2013). Design optimization of full vehicle suspension based on ride and handling performance. FISITA 2012 World Automotive Congress, vol. 195 of Lecture Notes in Electrical Engineering, p. 75-86, https://doi.org/10.1007/978-3-642-33835-9_8

20. Skogestad Sigurd, Ian Postlethwaite. (2005). Multivariable Feedback Control, John Wiley \& Sons.

21. P. Dawei, K. Zhenxing, W.Xianhui, W. Hongliang, C. Shan. (2018). Design and experimental validation of control algorithm for vehicle hydraulic active stabilizer bar system. Proceedings of the Institution of Mechanical Engineers, Part D: Journal of Automobile Engineering, vol. 233, no. 5, p. 1280-1295, https:// doi.org/10.1177/0954407018770539

22. Van Tan Vu, Olivier Sename, Luc Dugard, Peter Gaspar. (2019). $H_{\infty} / L P V$ controller design for an active anti-roll bar system of heavy vehicles using parameter dependent weighting functions. Heliyon, vol. 5, no. 6, https://doi.org/10.1016/j.heliyon.2019. e01827

23. Andrzej Renski. (2001). Identification of Driver Model Parameters. International journal of occupational safety and ergonomics, vol. 7 , no. 1, p. 79-90, DOI: 10.1080/10803548.2001.1107647

\section{APPENDIX}

From Equation (12) the state equation for the car model can be written as:

$\dot{X}=E^{-1} A_{0} X+E^{-1} B_{01} W+E^{-1} B_{02} U$

Thus $A=E^{-1} A_{0} ; B_{1}=E^{-1} B_{01} ; B_{2}=E^{-1} B_{02}$. The matrices are defined as follows:

+) Matrix E:

$$
\begin{aligned}
& E=\left[\begin{array}{llll}
E_{11} & E_{12} & E_{13} & E_{14} \\
E_{21} & E_{22} & E_{23} & E_{24} \\
E_{31} & E_{32} & E_{33} & E_{34}
\end{array}\right] \\
& E_{11}=[I(7 \times 7)] \\
& E_{12}=[O(7 \times 7)] \\
& E_{13}=[O(6 \times 7)] \\
& E_{14}=[O(6 \times 7)] \\
& E_{21}=[O(9 \times 7)]
\end{aligned}
$$


$E_{22}=\left[\begin{array}{ccccccc}m_{s} & 0 & 0 & 0 & 0 & 0 & 0 \\ 0 & J_{x} & 0 & 0 & 0 & 0 & 0 \\ 0 & 0 & J_{y} & 0 & 0 & 0 & 0 \\ 0 & 0 & 0 & m_{1} & 0 & 0 & 0 \\ 0 & 0 & 0 & 0 & m_{2} & 0 & 0 \\ 0 & 0 & 0 & 0 & 0 & m_{3} & 0 \\ 0 & 0 & 0 & 0 & 0 & 0 & m_{4} \\ 0 & 0 & 0 & 0 & 0 & 0 & 0 \\ 0 & 0 & 0 & 0 & 0 & 0 & 0\end{array}\right]$

$E_{23}=\left[\begin{array}{llllll}0 & 0 & 0 & 0 & 0 & 0 \\ 0 & 0 & 0 & 0 & 0 & 0 \\ 0 & 0 & 0 & 0 & 0 & 0 \\ 0 & 0 & 0 & 0 & 0 & 0 \\ 0 & 0 & 0 & 0 & 0 & 0 \\ 0 & 0 & 0 & 0 & 0 & 0 \\ 0 & 0 & 0 & 0 & 0 & 0 \\ 1 & 0 & 0 & 0 & 0 & 0 \\ 0 & 1 & 0 & 0 & 0 & 0\end{array}\right]$

$E_{24}=\left[\begin{array}{cccccc}0 & 0 & 0 & 0 & 0 & 0 \\ 0 & 0 & 0 & 0 & 0 & -m h v \\ 0 & 0 & 0 & 0 & 0 & 0 \\ 0 & 0 & 0 & 0 & 0 & 0 \\ 0 & 0 & 0 & 0 & 0 & 0 \\ 0 & 0 & 0 & 0 & 0 & 0 \\ 0 & 0 & 0 & 0 & 0 & 0 \\ 0 & 0 & 0 & 0 & 0 & 0 \\ 0 & 0 & 0 & 0 & 0 & 0\end{array}\right]$

$E_{31}=E_{32}=[O(10 \times 10)]$

$$
E_{33}=\left[\begin{array}{cccccc}
0 & 0 & 4 \beta / \mathrm{V}_{t} & 0 & 0 & 0 \\
0 & 0 & 0 & 1 & 0 & 0 \\
0 & 0 & 0 & 0 & J_{a} & 0 \\
0 & 0 & 0 & 0 & 0 & 1 \\
0 & 0 & 0 & 0 & 0 & 0 \\
0 & 0 & 0 & 0 & 0 & 0 \\
0 & 0 & 0 & 0 & 0 & 0 \\
0 & 0 & 0 & 0 & 0 & 0 \\
0 & 0 & 0 & 0 & 0 & 0 \\
0 & 0 & 0 & 0 & 0 & 0
\end{array}\right]
$$

$E_{34}=\left[\begin{array}{cccccc}0 & 0 & 0 & 0 & 0 & 0 \\ 0 & 0 & 0 & 0 & 0 & 0 \\ 0 & 0 & 0 & 0 & 0 & 0 \\ 0 & 0 & 0 & 0 & 0 & 0 \\ 1 & 0 & 0 & 0 & 0 & 0 \\ 0 & 4 \beta / V_{t} & 0 & 0 & 0 & 0 \\ 0 & 0 & 1 & 0 & 0 & 0 \\ 0 & 0 & 0 & J_{a} & 0 & 0 \\ 0 & 0 & 0 & 0 & m v & 0 \\ 0 & 0 & 0 & 0 & 0 & J z\end{array}\right]$

$A_{0}=\left[\begin{array}{cccccccc}\multicolumn{2}{c}{A_{11}} & \multicolumn{2}{c}{A_{12}} & \multicolumn{2}{c}{A_{13}} & \multicolumn{2}{c}{A_{14}} \\ A_{21} & A_{22} & A_{23} & A_{24} & A_{25} & A_{26} & A_{27} & A_{28} \\ A_{31} & A_{32} & A_{33} & A_{34} & A_{35} & A_{36} & A_{37} & A_{38}\end{array}\right]$

$A_{11}=[O(7 \times 7)]$

$A_{12}=[I(7 \times 7)]$

$A_{13}=[O(6 \times 6)]$

$A_{14}=[O(6 \times 6)]$

$A_{22}=\left[\begin{array}{cccc}c_{1} & c_{2} & c_{3} & c_{4} \\ d c_{1} & d c_{2} & -c c_{3} & -c c_{4} \\ -a c_{1} & b c_{2} & b c_{3} & -a c_{4} \\ -\left(c_{1}+c_{t 1}\right) & 0 & 0 & 0 \\ 0 & -\left(c_{2}+c_{t 2}\right) & 0 & 0 \\ 0 & 0 & -\left(c_{3}+c_{t 3}\right) & 0 \\ 0 & 0 & 0 & -\left(c_{4}+c_{t 4}\right) \\ 0 & 0 & 0 & 0 \\ 0 & 0 & 0 & 0\end{array}\right]$

$A_{24}=\left[\begin{array}{cccc}k_{1} & k_{2} & k_{3} & k_{4} \\ d k_{1} & d k_{2} & -c k_{3} & -c k_{4} \\ -a k_{1} & b k_{2} & b k_{3} & -a k_{4} \\ -k_{1} & 0 & 0 & 0 \\ 0 & -k_{2} & 0 & 0 \\ 0 & 0 & -k_{3} & 0 \\ 0 & 0 & 0 & -k_{4} \\ 0 & 0 & 0 & 0 \\ 0 & 0 & 0 & 0\end{array}\right]$ 


$$
\begin{aligned}
& \begin{aligned}
A_{25}=\left[\begin{array}{ccc}
0 & 0 & 0 \\
0 & 0 & 0 \\
0 & 0 & 0 \\
0 & 0 & -A_{v 1} a_{a r n} / d \\
0 & 0 & 0 \\
0 & 0 & 0 \\
0 & 0 & A_{v 2} a_{a r n} / \mathrm{c} \\
0 & 1 & 0 \\
-w_{v}^{2} & -2 D_{v} w_{v} & 0
\end{array}\right] \quad A_{35}=\left[\begin{array}{ccc}
K_{q a} & 0 & -\left(\mathrm{K}_{c}+c_{l 2}\right) \\
0 & 0 & 0 \\
0 & 0 & V_{p} \\
0 & 0 & 0 \\
0 & 0 & 0 \\
0 & 0 & 0 \\
0 & 0 & 0 \\
0 & 0 & 0 \\
0 & 0 & 0 \\
0 & 0 & 0
\end{array}\right]
\end{aligned} \\
& A_{27}=\left[\begin{array}{ccc}
0 & 0 & 0 \\
0 & 0 & 0 \\
0 & 0 & 0 \\
0 & 0 & 0 \\
0 & 0 & -A_{v 1} a_{a r n} / d \\
0 & 0 & A_{v 2} a_{a r n} / \mathrm{c} \\
0 & 0 & 0 \\
0 & 1 & 0 \\
0 & 0 & 0
\end{array}\right] \\
& {\left[\begin{array}{ccc}
0 & 0 & 0 \\
0 & 0 & m h v \\
0 & 0 & 0
\end{array}\right] \quad\left[\begin{array}{lll}
0 & 0 & 0 \\
0 & 0 & 0
\end{array}\right]} \\
& A_{28}=\left[\begin{array}{ccc}
0 & 0 & 0 \\
0 & 0 & 0 \\
0 & 0 & 0 \\
0 & 0 & 0 \\
0 & 0 & 0 \\
0 & 1 & 0 \\
0 & 0 & 0
\end{array}\right] \\
& A_{26}=[O(3 \times 9)] \\
& A_{31}=[O(10 \times 3)] \\
& A_{32}=[O(10 \times 4)] \\
& A_{33}=[O(10 \times 3)] \\
& A_{34}=[O(10 \times 4)] \\
& A_{36}=\left[\begin{array}{ccc}
-V_{p} & c_{l 1} & 0 \\
0 & 1 & 0 \\
0 & -d_{a} & 0 \\
0 & 0 & 0 \\
0 & 0 & -w_{v}^{2} \\
0 & 0 & K_{p a} \\
0 & 0 & 0 \\
0 & 0 & 0 \\
0 & 0 & 0 \\
0 & 0 & 0
\end{array}\right] \\
& A_{37}=\left[\begin{array}{ccc}
0 & 0 & 0 \\
0 & 0 & 0 \\
0 & 0 & 0 \\
1 & 0 & 0 \\
-2 D_{v} w_{v} & 0 & 0 \\
0 & -\left(K_{c}+c_{12}\right) & -V_{p} \\
0 & 0 & 0 \\
0 & V_{p} & 0 \\
0 & 0 & 0 \\
0 & 0 & 0
\end{array}\right]
\end{aligned}
$$




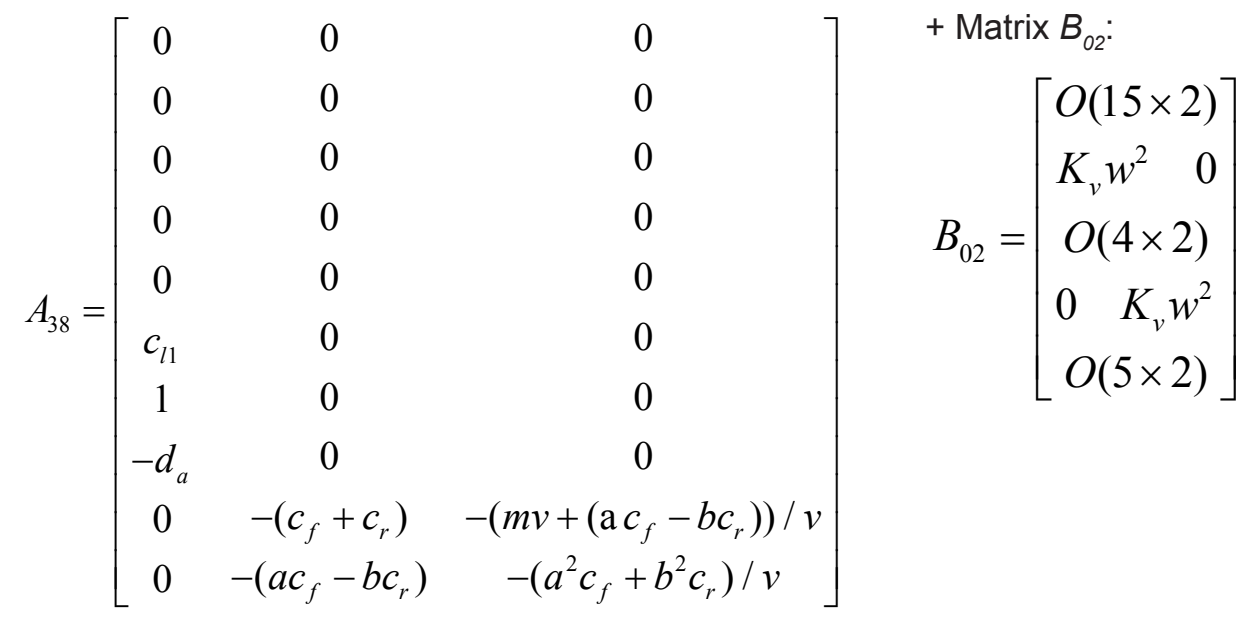

+ Matrix $B_{01}$ :

$$
B_{01}=\left[\begin{array}{cccccc}
\multicolumn{7}{c}{O(10 \times 5)} \\
c_{t 1} & 0 & 0 & 0 & 0 \\
0 & c_{t 2} & 0 & 0 & 0 \\
0 & 0 & c_{t 3} & 0 & 0 \\
0 & 0 & 0 & c_{t 4} & 0 \\
& O(10 \times 5) & \\
0 & 0 & 0 & 0 & c_{f} \\
0 & 0 & 0 & 0 & a c_{f}
\end{array}\right]
$$

